\title{
Substandard Performance in Mathematical Problem Solving in Physics Among Higher Secondary School Students in Kerala - An Investigation on Teacher Perceptions and Student Difficulties
}

\author{
NS Mumthas* and Shyma Usman Abdulla \\ Farook Training College P.O. Calicut, Kerala-673632, India
}

*Email: mumthasns@yahoo.co.in

\section{ARTICLE INFORMATION}

Received: October 03, 2018

Revised: December 13, 2018

Accepted: February 22, 2019

Published online: March 04, 2019

\section{Keywords:}

Physics Education, Substandard Performance, Categories of Difficulties in Mathematical Problem Solving, Higher Secondary School Students

\begin{abstract}
Physics and Mathematics are two deeply interlinked domains of Science. Mathematics is considered as the language in which the Physics theories are built by employing mathematical symbols and operations to make equations and representations in the world of Physics completely meaningful. In spite of being the backbone of Physics, the use of Mathematics principles and operations in Physics is the root cause of most of the issues and hassles aroused among students who learn Physics. This is an investigation on the substandard performance in mathematical problem solving in Physics among higher secondary school students by looking into the responses of teachers and students. The responses obtained from 21 higher secondary Physics teachers through questionnaire were studied using percentage analysis and the four major categories of 'Difficulties in Mathematical Problem Solving in Physics' faced by students viz., 'Creating or Identifying the Formula', 'Extracting Information from Diagrams', 'Using Physics Concepts to Create Schematic Diagrams' and 'Application of Mathematics' to solve Physics problems, were identified. The investigators used 'Test on Mathematical Problem Solving in Physics' with 40 multiple choice questions on select basic topics from 'Motion', which was informed by the Physics teachers to be one of the strenuous concepts for students while solving problems. The extent of each category of difficulty in the respective topics based on the students' responses in the test was studied to rank them. This study also highlights some suggestions for improving the teaching and learning of mathematical problems in Physics at higher secondary level.
\end{abstract}

to fulfil the country's rising demand is the predominant

\section{Introduction}

In the contemporary world, there is an expeditious growth of Science and Technology. This rapid development has phenomenally reshaped peoples' life on earth. From the way of thinking to action; it is the technology and innovation that is in demand. Science and Technology is the working engine, not only in the growth of man, but also at the societal and national level. The build-up of scientific knowledge and advanced technologies has paved the way to economic, political and social transformations within the nation (UNESCO, 2012).

Scientific and technological progress requires the development of Science Education. Science Education imparts better standards for the mass and escort to cultural advancement, revitalizing the development of potential scientific and technological manpower. According to the Scientific Policy Resolution, 1958, vigorous cultivation of Science and its implementation attribute of the $21^{\text {st }}$ century world. Thus, the cultivation of a generation who are superior utilizers of the fruits of Science by disseminating the spirit of scientific inquiry is impossible without Science Education (Ministry of Science and Technology, Government of India, 1958). The World Science Forum (2013) declared that "providing high quality education in Science, Technology and Engineering must be understood as a priority: in basic education, as a fundamental element of modern culture and later as a vital component of a country's capacity to compete in the global economy" (Hungarian Academy of Sciences, 2013).

In schools, being at the grass root level, intense methods and provisions for the promotion of Science should be ensured. School education is the formal means which provides structured environment for teaching-learning process to take place. Structured environment incorporating elements such as 
curriculum, models of organization, pattern and arrangement of physical learning spaces, interactions between teacher and pupil, approaches of assessment and evaluation, educational activities etc., should be outlined and executed which would inculcate the potential of scientific thinking and inquiry in pupils effectively.

At this juncture, the relevance of incorporation of Science as a school discipline with the aim of nurturing scientific skills is evident. The Secondary Education Commission (1952-53) has recommended that every secondary school pupil should study General Science as a compulsory subject, so that he gains a basic quantum of scientific knowledge as a part of his General Education (Ministry of Education, Government of India, 1953). The Ministry of Education, Government of India (1966) had also laid noteworthy relevance on Science and had recommended the discipline to be incorporated in the school curriculum and to be taught on a compulsory basis as a part of General Education during the first ten years of schooling.

According to the Twelfth Five-Year Plan (201217), Education of Science and Mathematics need notable attention of the educational administrators. "Poor Science and Mathematics Education accounts for 80 percent of total students who fail in Tenth Board Examination. The transition rate from X to XI in Science is very small as indicated by less than 12 percentage share of students in UG Science stream. This low enrolment in Science stream at higher secondary level and poor quality education is a constraint in development of scientific manpower in the country" (Planning Commission, Government of India, 2013).

Within the various domains of Science, Physics is a significant and essential discipline which students encounter throughout their secondary school stages. It remains the same for those learners who are interested to pursue higher education in any of the branches of Science. Although its relevance-is known, there has been a drastic fall in the performance in Physics among students (Barmby \& Defty, 2006; Oon \& Subramaniam, 2010; Awodun, Oni \& Aladejana, 2014; Mekonnen, 2014; Stephen, 2016).

Physics and Mathematics are two deeply interlinked 'arms' of Science (Karam, Pospiech \& Pietrocola, 2011). Mathematics is considered as the language in which the Physics theories are built by employing Mathematical symbols and operations to make equations and representations in the world of Physics completely meaningful (Redish, 2005). In short, relationship between these two streams is identified to be noteworthy by both physicist and Mathematicians (Al-Omari \& Miqdadi, 2014) due the technical, structural and communicative roles of Mathematics in Physics (Ataide \& Greca, 2013; Pospiech, 2015).

Many researches in the field of Physics Education have been conducted to explore the relationship between Mathematical skills and Physics achievement of students. There has been mushrooming of the notion that a student who performs well in Mathematics is expected to showcase better performance in Physics too (Jiar \& Long, 2014). "A student's development as a physicist entails, in no small part, becoming increasingly comfortable with Mathematics" (Bing \& Redish, 2009). Thus, there was no need of any hesitation to establish the existence of positive association between the skills and scores in these disciplines (Cohen, Hillman \& Agne, 1978; Delialioglu \& Askar, 1999; Jiar \& Long, 2014; Lacambra, 2016).

In spite of being the backbone of Physics, the employment of Mathematics principles and operations in Physics is the root cause of most of the issues and hassles aroused among students who learn Physics (Bing, 2008). Physics is considered to be a particularly difficult school discipline due to the issues encountered by the students in integrating the concepts of Mathematics and Physics (Tuminaro, 2004; Pietrocola, 2008; Vinitsky-Pinsky \& Galili, 2014; Mwangala \& Shumba, 2016). This can be observed in student difficulty in setting up an appropriate calculation and also in interpreting the results of the calculation in the context of a Physics problem (Tuminaro \& Redish, 2007).

This study makes an attempt to investigate into the issue of Substandard Performance in Mathematical Problem Solving in Physics among Higher Secondary School Students in Kerala by analysing the responses of teachers and students.

\section{Research Questions}

The research questions framed for the purpose of the study are as follows.

1. What are the major categories of 'Difficulties in Mathematical Problem Solving in Physics' faced by 
Higher Secondary School Students as perceived by their teachers?

2. What is the extent of each category of 'Difficulty in Mathematical Problem Solving in Physics' faced by Higher Secondary School Students?

3. What is the relative position of select basic topics from 'Motion' based on the extent of each category of 'Difficulty in Mathematical Problem Solving in Physics' faced by Higher Secondary School Students?

\section{Methodology}

\subsection{Method and Sample}

The study had adopted survey method which was conducted on a sample of 500 higher secondary school students (Male-250, Female-250; Rural-333, Urban-167; Government-250; Aided-125, Unaided-125) from Kerala drawn using stratified sampling technique.

\subsection{Tools used}

The tools, viz., 'Questionnaire on Teacher Perceptions of Student Difficulties' and 'Test on Mathematical Problem Solving in Physics' were prepared by the investigators.

The questionnaire for teachers consists of 12 items in total. Out of these, first 2 items were framed to pool the basic topics in Physics which the students found tough, both to comprehend and reproduce. The rest 10 items were structured by the investigators in such a way to elicit the types of difficulties faced by higher secondary school students while attending to Mathematical problems in Physics. The reliability of the questionnaire was ensured using test-retest method, in which no wide variation between the responses in both the tests was found upon cross checking. Face validity and content validity of the tool were also established.

Based on the major categories of 'Difficulties in Mathematical Problem Solving in Physics' that students encountered, the investigators prepared 'Test on Mathematical Problem Solving in Physics' with 40 multiple choice questions on select basic topics from 'Motion', which were suggested by teachers through questionnaire. The topics included are 'Distance', 'Displacement', 'Speed', 'Velocity' and 'Acceleration'. The test contains two items from each select topic for measuring the extent of each category of difficulty. The reliability of the test was ensured using test-retest method $(r=0.79)$. Face validity, content validity and criterion related validity $(r=0.74)$ of the test were also established.

\subsection{Statistical Technique}

Percentage analysis of responses of teachers and students obtained through questionnaire and test respectively were used for satisfying the objectives of the study.

\section{Analysis and Interpretation}

\subsection{Categories of 'Difficulties in Mathematical} Problem Solving in Physics' faced by Higher Secondary School Students as perceived by their teachers

As the primary objective of the study was meant to identify the teacher perception on the major categories of 'Difficulties in Mathematical Problem Solving in Physics' faced by Higher Secondary School Students, the responses obtained through the questionnaire were analysed and sorted.

Upon sorting of the responses, the investigators found that majority of the teachers held the opinion that the questions from the concept 'Motion' is prone to mistakes while attempting mathematical problems in Physics. The teachers also added that this concept is being introduced to the students in VIII standard and they have the same taught in IX and XI standards in the later years of schooling. Even then, students commit a lot of errors while answering problems involving mathematical application from 'Motion' especially in the topics viz., 'Distance', 'Displacement', 'Speed', 'Velocity' and 'Acceleration'.

By analysing and sorting the responses of teachers obtained for the items based on difficulties generally encountered by students in Mathematical Problem Solving in Physics, the investigators consolidated with the four major categories of difficulties, viz.,

1. Creating or Identifying the Formula

2. Extracting Information from Diagrams

3. Using Physics Concepts to Create Schematic Diagrams

4. Application of Mathematics

The percent of teachers who perceived the respective category of Difficulty in Mathematical Problem Solving in Physics is shown in Figure 1. 


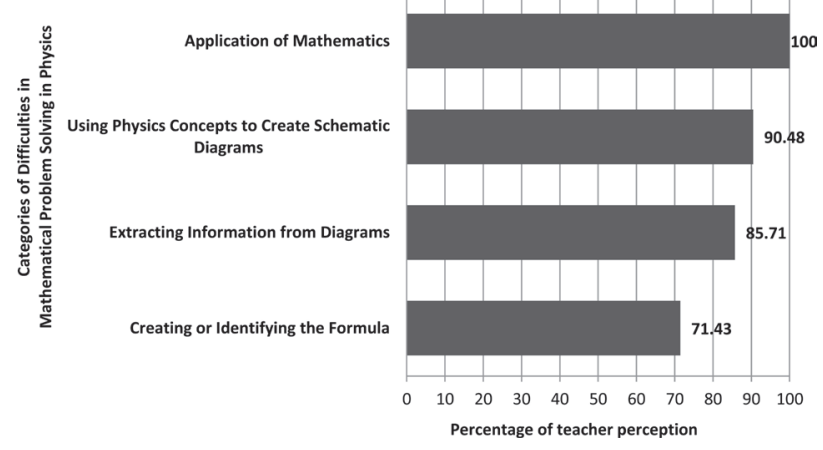

Figure 1: Percent of teachers who perceived the respective category of difficulty in mathematical problem solving in physics.

Figure 1 reveals that all teachers held the common opinion that the major difficulty that higher secondary students faced was in the 'Application of Mathematics', which was followed by about 91 percent of teacher perception with the difficulty in 'Using Physics Concepts to Create Schematic Diagrams'. Nearly 86 percent of teachers were with the view point that 'Extracting Information from Diagrams' was difficult task for pupils, while 71 percent of teachers perceived with the student difficulty in 'Creating and Identifying the Formula'.

\subsection{Extent of each category of Difficulty in} Mathematical Problem Solving faced by Higher Secondary School Students in select basic topics from 'Motion'

\subsubsection{Extent of Difficulty in the Category 'Creating or Identifying the Formula'}

The percent of students with difficulty in 'Creating or Identifying the Formula' in the select basic topics from 'Motion' is shown in Figure 2.

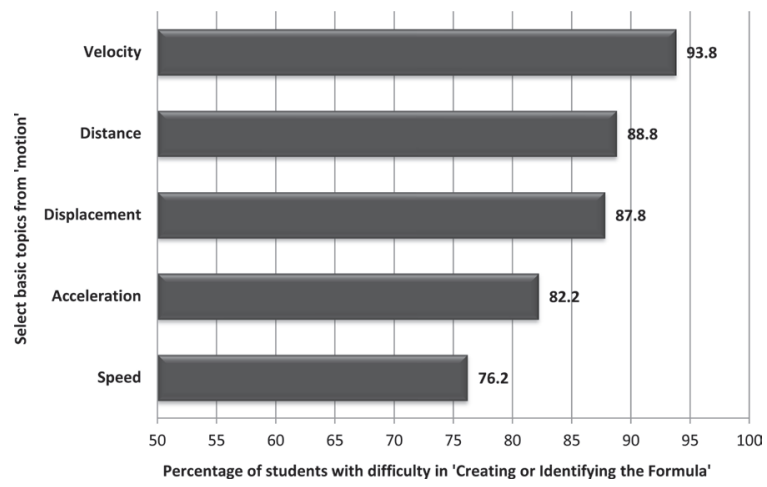

Figure 2: Percent of students with difficulty in 'creating or identifying the formula' in select basic topics from 'motion'.
Figure 2 explains that while considering the category of difficulty in 'Creating or Identifying the Formula', its extent is highest in 'Velocity' (94\%), which is followed by 'Distance' (89\%), 'Displacement' (88\%), 'Acceleration' (82\%) and the lowest in 'Speed' (76\%).

This throws light upon the fact that almost all students have the difficulty in 'Creating or Identifying the Formula' in 'Velocity'. Also, more than $3{ }_{4}^{\text {th }}$ of the students faces the same category of difficulty in the topics 'Distance', 'Displacement', 'Acceleration' and 'Speed'.

\subsubsection{Extent of difficulty in the category 'Extracting Information from Diagrams'}

The percent of students with difficulty in 'Extracting Information from Diagrams' in select basic topics from 'Motion' is shown in Figure 3.

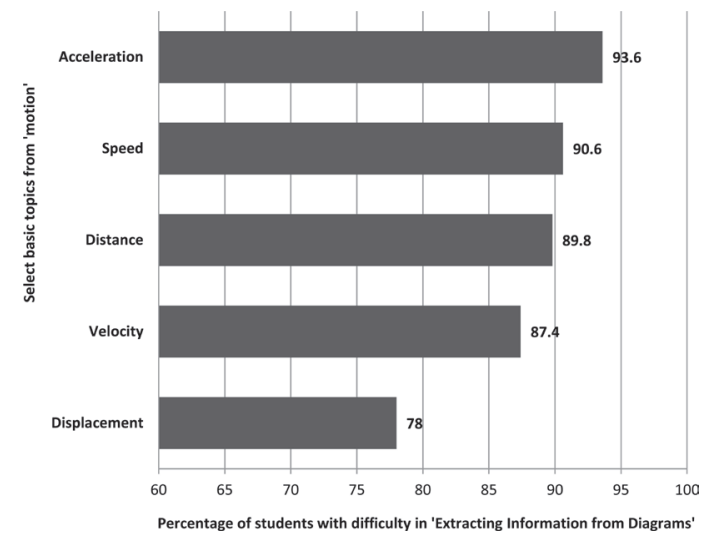

Figure 3: Percent of students with difficulty in 'extracting information from diagrams' in select basic topics from 'motion'.

Figure 3 describes, while considering the category of difficulty in 'Extracting Information from Diagrams', its extent is highest in 'Acceleration' (94\%), which is followed by 'Speed' (91\%), 'Distance' (90\%), 'Velocity' $(87 \%)$ and the lowest in 'Displacement' (78\%).

Thus, this reveals that almost all students face difficulty in 'Extracting Information from Diagrams' in the topic 'Acceleration'. When it comes to the topics like 'Speed', 'Distance', 'Velocity' and 'Displacement', more than $3 /{ }^{\text {th }}$ of the students possess the same category of difficulty.

\subsubsection{Extent of difficulty in the category 'Using Physics Concepts to Create Schematic Diagrams'}

The percent of students with difficulty in 'Using Physics Concepts to Create Schematic Diagrams' in select basic topics from 'Motion' is shown in Figure 4. 


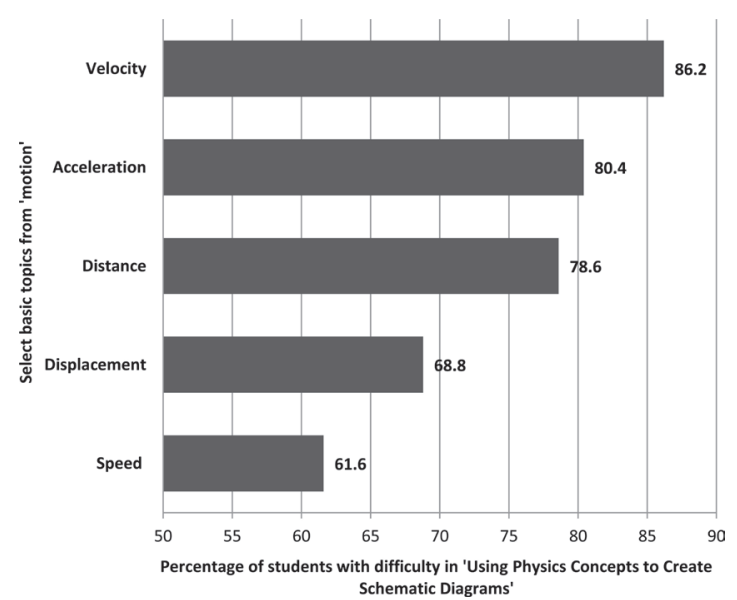

Figure 4: Percent of students with difficulty in 'using Physics concepts to create schematic diagrams' in select basic topics from 'motion'.

Figure 4 shows that while considering the category of difficulty in 'Using Physics Concepts to Create Schematic Diagrams', its extent is highest in 'Velocity' (86\%), which is followed by 'Acceleration' (80\%), 'Distance' (79\%), 'Displacement' (69\%) and the lowest in 'Speed' (62\%).

This makes clear of the fact that more than $3 /{ }_{4}^{\text {th }}$ of the students possess Difficulty in 'Using Physics Concepts to Create Schematic Diagrams' within the topics 'Velocity', 'Acceleration' and 'Distance'. About $2 / 3$ ' of the students have the same category of difficulty in 'Displacement' and 'Speed'.

\subsubsection{Extent of difficulty in the category 'Application of Mathematics'}

The percent of students with difficulty in 'Application of Mathematics' in select basic topics from 'Motion' is shown in Figure 5.

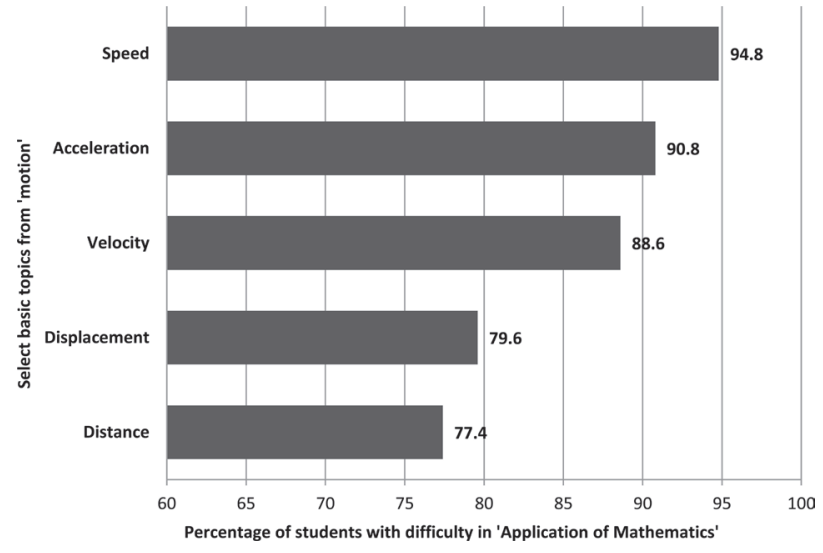

Figure 5: Percent of students with difficulty in 'application of mathematics' in select basic topics from 'motion'.
Figure 5 shows that while considering the category of difficulty in 'Application of Mathematics', its extent is highest in 'Speed' (95\%), which is followed by 'Acceleration' (91\%), 'Velocity' (89\%), 'Displacement' $(80 \%)$ and the lowest in 'Distance' $(77 \%)$.

So, it is evident that most of the students have difficulty in 'Application of Mathematics' in 'Speed' and 'Acceleration' and more than $3 /{ }_{4}$ th of the students have the same difficulty in the topics 'Velocity', 'Displacement' and 'Distance'.

\section{Conclusion}

The results of the study helps the investigators to reach the conclusion that the higher secondary school students in Kerala who have opted science as their main stream, generally have a high extent of Difficulty in Mathematical Problem Solving in Physics. The four major categories of this difficulty identified based on teacher perceptions can be listed as

1. Creating or Identifying the Formula

2. Extracting Information from Diagrams

3. Using Physics Concepts to Create Schematic Diagrams

4. Application of Mathematics

The higher secondary students are meant to be very much familiarised with the basic concepts in 'Motion' so as to possess a remarkable level of conceptual knowledge in it. They have been coming across the various basic topics like 'Distance', 'Displacement', 'Speed', 'Velocity' and 'Acceleration' from their high school classes itself, specifically, VIII and IX standard. In XI standard they even learn higher order and advanced concepts regarding 'Motion'. But still they have high level of difficulty in 'Creating or Identifying the Formula', 'Extraction of Information from Diagrams', 'Using Physics Concepts to Create Schematic Diagrams' and 'Application of Mathematics', while solving mathematical problems in the very grass root level topics in 'Motion' using their conceptual knowledge.

Also, the extent of difficulty faced by higher secondary students for each topic varies from category to category. For example, it can be observed that difficulty in 'Application of Mathematics' is highest in the topic 'Speed', while it is the topic with least difficulty in 'Creating or Identifying the Formula' and 'Using Physics Concepts to Create Schematic Diagrams'. For getting the summary of similar results 
at a glance, the ranking of select basic topics from 'Motion' based on the extent of each category of
'Difficulty in Mathematical Problem Solving' is given as Table 1.

Table 1: Ranking of Select Basic Topics from Motion' based on the Extent of Difficulty in each Category.

\begin{tabular}{|l|l|l|l|}
\hline $\begin{array}{l}\text { Creating or Identifying the } \\
\text { Formula }\end{array}$ & $\begin{array}{l}\text { Extraction of Information } \\
\text { from Diagrams }\end{array}$ & $\begin{array}{l}\text { Using Physics Concepts to } \\
\text { Create Schematic Diagrams }\end{array}$ & Application of Mathematics \\
\hline 1. Velocity & 1. Acceleration & 1. Velocity & 1. Speed \\
\hline 2. Distance & 2. Speed & 2. Acceleration & 2. Acceleration \\
\hline 3. Displacement & 3. Distance & 3. Distance & 3. Velocity \\
\hline 4. Acceleration & 4. Velocity & 4. Displacement & 4. Displacement \\
\hline 5. Speed & 5. Displacement & 5. Speed & 5. Distance \\
\hline
\end{tabular}

The average percentage difficulty in 'Mathematical Problem Solving in Physics' is highest in 'Velocity' (89\%), which is followed by 'Acceleration' (87\%), 'Distance' (84\%), 'Speed' (81\%) and the lowest in 'Displacement' (79\%). From this, it is evident that $80-90 \%$ of the higher secondary school students who have opted science as their main stream face 'Difficulty in Mathematical Problem Solving in Physics', which is one of the important reasons for their overall substandard performance in learning Physics.

\section{Educational Implications}

Since the findings of the study show that the higher secondary school students in Kerala have difficulty in 'Creating or Identifying the Formula', 'Extraction of Information from Diagrams', 'Using Physics Concepts to create Schematic Diagrams' and 'Application of Mathematics' in the context of Physics problem solving, the investigators put forward the following suggestions to improve teaching-learning process of mathematical problems in Physics.

- Well-designed instructional approach incorporating technologies have to be adopted while teaching mathematical problems in Physics. This would render in easy comprehension of the technical role of Mathematics in the discipline especially in deriving formulas, transforming Physics concepts to diagrammatic representations and vice versa, rearranging and solving equations etc.

- Mathematics and Physics are two disciplines which should never be taught in isolation from one another.
Teachers handling both the disciplines have to take enough measures to work and plan blended instructional approach to transact them. Specialization based team teaching can be adopted to utilize the interdisciplinary nature of both the school subjects to a maximum extent. This would indeed enhance the procedural skills needed for solving mathematical problems in Physics, such as reading Physics information from graphs, constructing diagrams using Physics concepts and simplification of equations.

- Linking of Physics and Mathematics concepts with real life situations is necessary for students to provide the confidence to apply what they have learnt to various situations

- beyond the school and classroom. Teachers should focus mainly on bridging concepts with the familiar situations for the students since their 'ability for application' implies the 'real learning'.

- Teachers should never be reluctant in measuring the prerequisites of the students before introducing new concepts. Ignoring their level of previous knowledge might turn to be one of the reasons for the multiplication of difficulty in learning the discipline and this would in turn hinder the vertical transfer of knowledge, as in the case of substandard mathematical skills depicted by students in Physics problem solving.

- The potholes in students' calibre in application of mathematical principles and concepts to solve Physics problems have to be diagnosed and filled up with proper remedial assistance and tutorial sessions in both Physics and Mathematics.

- Equal attention and weightage should be laid down by the teachers while teaching Physics theories as well as mathematical problems related to it. Then only students 
would take keen effort for building their mathematical skills by becoming aware of the fact that mathematical exercises are not something to be ignored.

- Regular practicing of problem based exercises in connection to every learnt concept is very important. Formative assessments must be strengthened with more problem-based drills, worksheets and assignments guaranteeing ample practice and exposure to mathematical exercises and tasks.

- Systematic monitoring in each and every step in problem solving task is very important. Students should be supervised and taught how to start with the problem and to advance step wise into the correct solution.

- Students should be encouraged to take part in school based programmes and activities connecting Mathematics and Physics such as science-math quiz competitions,

- seminars, open forums, discussions etc., so that such ventures from the part of the school exposes students to the technical and communicative roles played by Mathematics in Physics, like, derivation of formulas, translation of math-representations into Physics, identifying Physics interpretations out of graphs and diagrams and application of mathematical operations to rearrange and solve equations to reach the solution.

- Physics teachers in Kerala are burdened with the exhaustive subject to be taught to a large group of students within a small span of time. This inconvenience can be tackled by employing MOODLE platforms in which the mathematical exercises and worksheets can be circulated and student evaluation can be performed efficiently. This would also provide enough scope for building the practice of self-learning among the pupils.

By the incorporation of above suggestions through synergetic involvement and integrative efforts of school administrators and teachers, we can expect a mass of students with better Physics expertise in various dimensions of mathematical applications in Physics, leading to better Physics education as a whole.

\section{References}

Al-Omari, W., \& Miqdadi, R. (2014). The epistemological perceptions of the relationship between Physics and Mathematics and its effect on problem-solving among pre-service teachers at Yarmouk University in Jordan. International Education Studies, 7(5), 39-48. http://dx.doi.org/10.5539/ies.v7n5p39

Ataide, A., \& Greca, I. (2013). Epistemic views of the relationship between physics and mathematics: Its influence on the approach of undergraduate students to problem solving. Science \& Education, 22(6), 1405-1421. Retrieved from http://dx.doi.org/10.1007/s11191-012-9492-2

Awodun, A.O., Oni, S. A., \& Aladejana, A. L. (2014). Students' variables as predictor of secondary school students' performance in physics. International Journal of Scientific and Research Publications, 4(8), 1-5. Retrieved from http://www.ijsrp.org/researchpaper-0814/ijsrp-p3293.pdf

Barmby, P., \& Defty, N. (2006). Secondary school pupils' perceptions of physics. International Journal of Science Education, 24(2), 199-215. Retrieved from https:// doi.org/10.1080/02635140600811585

Bing, T. J. (2008). An epistemic framing analysis of upper level physics students' use of mathematics (Unpublished doctoral dissertation). The University of Maryland, Washington D. C. Retrieved from www.Physics.umd. edu/perg/dissertations/Bing/BingDissertation.pdf

Bing, T. J., \& Redish, E. F. (2009). Analyzing problem solving using math in physics: Epistemological framing via warrants. Physics Education Research, 5(2), 02010801-02010815. Retrieved from www2.Physics. umd.edu/ redish/Papers/BingRedish-EpistFraming. pdf

Cohen, H. D., Hillman, D. F., \& Agne, R. M. (1978). Cognitive level and college physics achievement. American Journal of Physics, 46, 1026-1029. Retrieved from https://doi.org/10.1119/1.11422

Delialioglu, O., \& Askar, P. (1999). Contribution of students' mathematical skills and spatial ability to achievement in secondary school physics. Hacettepe University Egitim

Fakultesi Dergisi, 16(17), 34-39. Retrieved from http://www.efdergi.hacettepe.edu.tr/yonetim/icerik/ makaleler/1199-published.pdf

Hungarian Academy of Sciences. (2013). Declaration of World Science Forum 2013, Rio de Janeiro. Retrieved from

https://worldscienceforum.org/contents/declarationof-world-science-forum-2013-110033

Jiar, Y. K., \& Long, C. Y. (2014). Mathematical thinking and physics achievement of secondary school students. Sains Humanika, 2(4), 446-452. Retrieved from www. fp.utm.my/ePusatSumber/listseminar/medc2012/ pdf/57.pdf

Karam, R., Pospiech, G., \& Pietrocola, M. (2011). Mathematics in physics lessons: Developing structural skills. Paper Presented at GIREP-EPEC \& PHEC 2009 International Conference August 17-21, University of Leicester, UK. Retrieved from http://www.univreims.fr/site/evenement/girep-icpe-mptl-2010-reims- 
international-conference/gallery_files/site/1/90/4401/ 22908/29476/30505.pdf

Lacambra, W. T. (2016). Students' academic performance in Physics 1: Basis for teaching and learning enhancement. Research on Humanities and Social Sciences, 6(4), 78-84. Retrieved from www.iiste.org/Journals/index.php/RHSS/article/ download/28956/29719

Mekonnen, S. (2014). Problems challenging the academic performance of physics students in higher governmental institutions in the case of Arbaminch, Wolayita Sodo, Hawassa and Dilla universities. Scientific Research, 6(5), 362-375. Retrieved from http://file.scirp.org/ pdf/NS_2014031710440008.pdf

Ministry of Education, Government of India. (1953). Report of the Secondary Education Commission 1952-53. Delhi-6: The Manager of Publications, Government of India Press.

Ministry of Education, Government of India. (1966). Report of the Education Commission 1964-66. New Delhi: The Manager of Publications, Government of India Press.

Ministry of Science and Technology, Government of India. (1958). Scientific Policy Resolution 1958. Retrieved from http://www.nrdms.gov.in/sci_policy.asp

Mwangala, K. P., \& Shumba, O. (2016). Physicomathematical conceptual difficulties among first year students learning introductory university physics. American Journal of Educational Research, 4(17), 1238-1244. Retrieved from http://pubs.sciepub.com/ education/4/17/8/index.html

Oon, P. T., \& Subramaniam, R. (2010). On the declining interest in physics among students From the perspective of teachers. International Journal of Science Education, 33(5), 727-746. Retrieved from https:// doi.org/10.1080/ 09500693.2010.500338

Pietrocola, M. (2008). Mathematics as structural language of physical thought. In M. Vicentini, \& E. Sassi (Eds.), Connecting research in physics education with teacher education. Retrieved from https://web.phys.ksu.edu/ icpe/Publications/teach2/Pietrocola.pdf

Planning Commission, Government of India. (2013). Twelfth five year plan 2012-17. New Delhi: Sage Publications.
Pospiech, G. (2015). Interplay of mathematics and physics in physics education. In A. Beckmann, V. Freiman, \& C. Michelsen (Eds.), Mathematics and its connections to the arts and sciences. Ebook proceedings of the International Symposium MACAS -2015 (pp. 3643). Hildesheim: Verlag Franzbecker. Retrieved from http://www. franzbecker.de/langfassung/760.pdf

Redish, E. F. (2005). Problem solving and the use of math in physics courses. Paper presented at the conference, World View on Physics Education in 2005: Focusing on Change, Delhi, India. Retrieved from http://arxiv. org/ftp/Physics/papers/0608/ 0608268.pdf

Stephen, S. G. (2016). Students' academic performance in physics, chemistry and biology: A case study of some selected secondary schools in Fagge local government of Kano state (Unpublished graduation project). The Department of Science and Technology Education, Bayero University, Kano. Retrieved from https://www.researchgate.net/ publication/318888505_pdf

Tuminaro, J. (2004). A cognitive framework for analyzing and describing introductory students' use and understanding of mathematics in physics (Unpublished doctoral dissertation). The Graduate School of the University of Maryland, College Park. Retrieved from http:// www.Physics.umd.edu/perg/dissertations/Tuminaro/ Tuminaro PhD.pdf

Tuminaro, J., \& Redish, E. F. (2007). Elements of a cognitive model of physics problem solving: Epistemic games. Physics Education Research, 3(2). Retrieved from https://journals.aps.org/prper/pdf/10.1103/ PhysRevSTPER.3.020101

UNESCO. (2012). Science and Technologies for Knowledge Societies: What Role for UNESCO in 2014-2021? France: UNESCO Publishing. Retrieved from http:// www.unesco.org/new/fileadmin/MULTIMEDIA/ HQ/SC/pdf/Consultation_Scie nce_Technology_for_ Knowledge_Societies_En.pdf

Vinitsky-Pinsky, L. \& Galili, I. (2014). The need to clarify the relationship between physics and mathematics in science curriculum: Cultural knowledge as possible framework. Procedia -Social and Behavioral Sciences, 116, 611-616. Retrieved from https://doi. org/10.1016/j.sbspro.2014.01.266 


\section{Issues and Ideas in Education}

Chitkara University, Saraswati Kendra, SCO 160-161, Sector 9-C, Chandigarh, 160009, India

Volume 7, Issue 1

March 2019

ISSN 2320-7655

Copyright: [@ 2019 NS Mumthas and Shyma Usman Abdulla] This is an Open Access article published in Issues and Ideas in Education (Issues Ideas Educ.) by Chitkara University Publications. It is published with a Creative Commons Attribution- CC-BY 4.0 International License. This license permits unrestricted use, distribution, and reproduction in any medium, provided the original author and source are credited. 